\title{
Evaluation of dynamic connection designs for road safety barriers
}

\author{
D. A. F. Bayton \\ Corus, Construction and Engineering Products, Newport, UK
}

\begin{abstract}
Bolted road safety barrier connections utilise slotted holes that are perpendicular to the direction of the safety barrier beam. Typically, eight M16 bolts are needed in a lap joint configuration to make each connection. The design of the lap joint connection has remained unchanged for several years.

Previous research work has successfully determined the performance characteristics of the bolted connections at quasi-static velocities. Performance improvements at quasi-static velocities have been identified. Therefore, representative test coupons using different design configurations to that of the original test coupon were examined at dynamic velocities.

The laboratory test results show that improvements can be made if the current lap joint design were to be changed. Performance improvements such as the amount of energy that the connection was able to absorb and the maximum connection system force were observed.
\end{abstract}

Keywords: safety barrier, crash performance, fastener, connection, dynamic performance.

\section{Introduction}

The performance of road safety barrier connections is not directly linked to advances in vehicle technology. The UK government has recently released a specification for road restraint systems that has resulted in the transfer of design responsibility to industrial safety barrier manufacturers (BSI [1]).

Whilst there has been a great incentive to improve the prospect of occupant survivability through improvements to the vehicle design (Birch et al [2]), it would seem safety barrier designs have remained stagnant in the UK for several decades. The vehicle fleet found on the road has evolved, vehicles in use today 
cover a wide range of sizes, more than ever before, and there is a need to use different materials for certain parts of roadside hardware (Tabei et al [3]).

The use of bolted joints to connect structural members together and to transfer in-plane forces between them has been widely employed in civil, mechanical and aeronautic structures ( $\mathrm{Su}$ and $\mathrm{Siu}$ [4]). Bolted connections are extensively used in roadside safety barriers and their characteristics can directly affect the performance of the whole roadside barrier system. Corrugated beam safety barriers use double row bolted lap joints to make the connection between beam lengths. When an errant vehicle impacts the safety barrier system, each connection joint moves differently in relation to the distance from the impact point. When redirecting the vehicle away from the impact area, the safety barrier absorbs a significant amount of energy. Much of the impact energy is transmitted along the length of the barrier system. In general, bolted joints are mechanical connections between two components that will slip and allow for movement of one of the components in relation to the other along a specified direction (Reid and Hiser [5]). However in the case of corrugated beam safety barrier connections the slot is perpendicular to the barrier direction to aid with the construction of the barrier system. Tabei and $\mathrm{Wu}$ [3] report that in the experimental testing of the safety barrier system, it is observed that some bolted connections are subjected to very high forces that cause the bolts to shear through the corrugated beam. This could be compared to plane out shear reported by Kulak et al. [6]. Yet the joint does move prior to deformation of the connecting members upon impact of an errant vehicle, and this occurs because the slotted hole is significantly larger than the bolt diameter as well as due to plastic deformation of the actual safety barrier material (Bayton et al. [7]). Failure in bolted connections are similar to an "unbuttoning" effect that occurs after the connection has slipped i.e. moved and taken up all of its manufacturing tolerances (Oberg et al. [8]). Other failure modes include crushing of plate or bolt shank, tearing of the plate to the margin and tearing between fasteners (Oberg et al. [8]).

Dynamic tensile testing at different velocities was undertaken. Representative connection coupons were used to understand the energy absorbing properties of different connection designs when compared to the current four bolt connection design.

This study presents some initial results as to the increased performance that could be gained from subtle changes in design for the production of road safety barrier connections.

\section{Experimental}

The material used in the manufacture of the safety barrier beams is a structural steel known as S275. The composition of this steel grade is given in Table 1 (BSI [9]).

The S275 grade used for the test programme has a minimum yield strength of $275 \mathrm{MPa}$ in accordance to BS EN 10025-1-2004 Hot rolled products for structural steels (BSI [9]). 
Table 1: $\quad$ Chemical composition of S275 steel grade (BSI [9]).

\begin{tabular}{|c|l|l|l|l|l|l|l|l|}
\hline Steel Grade & $\begin{array}{l}\mathbf{C} \\
\text { Max. }\end{array}$ & $\begin{array}{l}\text { Mn } \\
\text { Max. }\end{array}$ & $\begin{array}{l}\mathbf{P} \\
\text { Max. }\end{array}$ & $\begin{array}{l}\mathbf{S} \\
\text { Max. }\end{array}$ & $\begin{array}{l}\mathbf{S i} \\
\text { Max }\end{array}$ & $\begin{array}{l}\mathbf{N 1 , 2} \\
\text { Max }\end{array}$ & $\begin{array}{l}\mathbf{N b} \\
\text { Min- } \\
\text { Max }\end{array}$ & $\begin{array}{l}\mathbf{V} \\
\text { Min- } \\
\text { Max }\end{array}$ \\
\hline S275 & 0.25 & 1.60 & 0.05 & 0.05 & 0.50 & - & - & - \\
\hline $\begin{array}{l}\text { Notes: } \\
\text { 1. It is permissible to exceed the specified values provided that for each increase of } \\
\text { 0.0015 nitrogen the phosphorous maximum content will be reduced by } 0.005 \% \text {; the } \\
\text { nitrogen content of the ladle analysis, however, shall not be more than } 0.012 \% .\end{array}$ \\
2. $\begin{array}{l}\text { The maximum value for nitrogen does not apply of the chemical composition shows a } \\
\text { minimum total aluminium content of } 0.020 \% \text { or if sufficient other nitrogen-binding } \\
\text { elements are present. The nitrogen-binding elements shall be mentioned in the } \\
\text { inspection document. }\end{array}$ \\
3. Values are in weight percentages.
\end{tabular}



Figure 1: $\quad$ Light optical and SEM micrographs of CMn S275 steel grade.

With the equipment that was available a dynamic velocity of $2.5 \mathrm{~ms}^{-1}$ was chosen in order to conduct tests with a certain amount of focus on a typical reality based strain rate. Additionally Dieter [10] states that a strain rate of $10^{-1}$ to $10^{2} \mathrm{~s}^{-1}$ should be used for dynamic tension or compression testing.

All of the equipment used in the subsequent tests was supplied by Corus RD\&T. In particular the following instruments were employed.

- MAND high rate tensile machine capable of a velocity of $2.5 \mathrm{~ms}^{-1}$.

- Resistance strain gauges with a measuring area of $5 \mathrm{~mm} \times 1.5 \mathrm{~mm}$.

- Strain gauges used in half bridge configuration with data logging equipment.

- Calibrated torque wrench.

- High speed video camera.

To ensure that there was as increased test accuracy, the quasi-static tests conducted previously also acted as a calibration exercise for the high rate testing. This is because the high rate tensile machine could not be fitted with a load cell to record the forces incurred during the test. The results from the calibration tests provided a basis on which to accurately calculate the Maximum Connection System Force (MCSF) for each connection. 
Each bolt was tightened using an elevated torque setting of $100 \mathrm{Nm}$ to give better preload accuracy and allow for the effect of friction between the nut and bolt threads as well as the washer faces $[8,11,12]$.

The connection configuration was assembled for test as shown in Figure 2. This was the basic configuration. Other designs were based on variations of this design. A matrix of the tested design configurations is shown in Table 2.

Connections with the bolt shank locked out against the edge of the slots were tested. In effect, optimum connections were tested without any undesired features such as loose bolts or connections that were able to move prior to plastic deformation of the connection material.

The containment section of the table refers to the depth of material between the edge of the first slot and the edge of the test coupon. Normally this dimension is $21.5 \mathrm{~mm}$ however this was increased for the High Containment (HC) coupon to $31.5 \mathrm{~mm}$. Other design variables included the addition of an extra bolt in the centre of the existing four bolt coupon. Also the slots were removed and clearance holes were used. The spacing $(216 \mathrm{~mm})$ between two bolt groups was reduced to $108 \mathrm{~mm}$. Therefore this represented four alternatives to the current connection design.

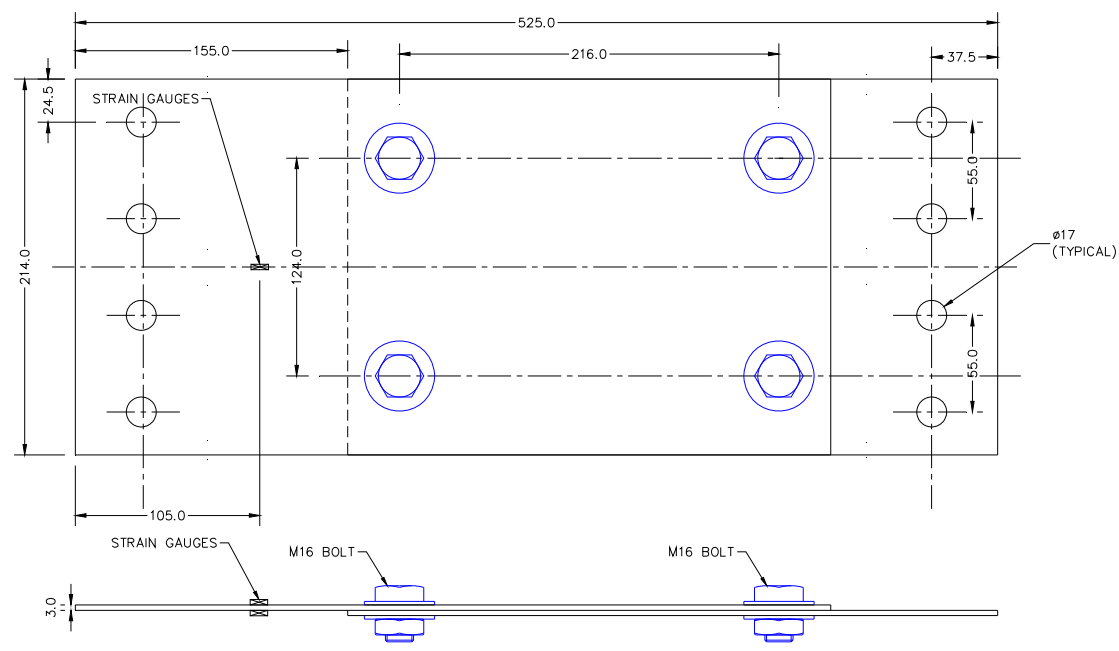

Figure 2: $\quad$ Four bolt connection test coupon.

Table 2: Connection configuration test matrix.

\begin{tabular}{|c|c|c|c|c|}
\hline Testing Matrix & Machine Cross Head Speed & \multicolumn{3}{|c|}{ Variables } \\
\hline Coupon & $2500 \mathrm{~mm} / \mathrm{sec}$ & Containment & Gauge & Material \\
\hline Std. Four Bolt & $\checkmark$ & $\mathrm{NC}$ & 3.00 & S275 \\
\hline Std. Four Bolt & $\checkmark$ & $\mathrm{HC}$ & 3.00 & S275 \\
\hline Five Bolt & $\sqrt{ }$ & $\mathrm{NC}$ & 3.00 & S275 \\
\hline Four Bolt Reduced & $\checkmark$ & $\mathrm{NC}$ & 3.00 & S275 \\
\hline Four Bolt (Holes) & $\checkmark$ & $\mathrm{NC}$ & 3.00 & S275 \\
\hline
\end{tabular}




\section{Results}

The fifteen tests that were conducted are summarised in Table 3 for the dynamic tensile testing. The Maximum Connection System Force (MCSF) has been presented along with the absorbed energy. Two failure modes were observed in the test coupons. Oberg et al. [8] and Nethercott [13] observed several typical failure modes for mechanically fastened connections and the failure modes of these test coupons can be defined as either plane out shear or tearing of the slot. Both failure modes occur after rotation of the bolts and local out of plane buckling of the connection members (Birch and Alves [2]). The connections could be defined both as shear connections and friction grip connections based on the observed failure mode path (Nethercott [13]). The observed failure modes are shown in Figure 3.

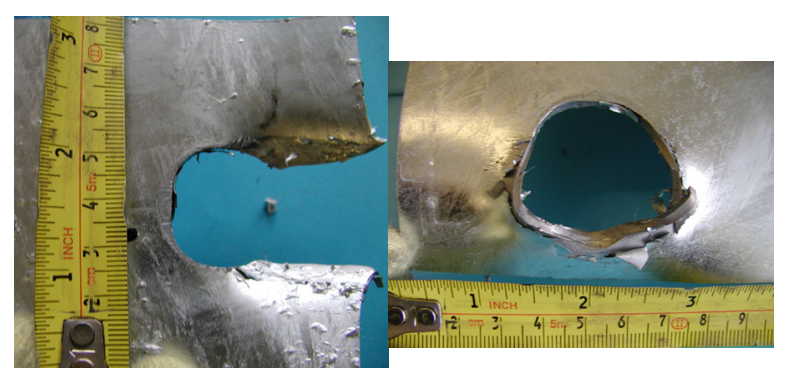

1. Plane Out Shear

2. Tear

Table 3: $\quad$ Observed connection failure modes.

Safety barrier connections are dynamic connections. Consequently, it is important not only to record the load versus displacement of each connection test but to calculate the amount of energy that the connection can absorb. Using the trapezoidal rule to calculate the area under the graph plot curve the amount of energy absorbed in Joules is recorded (Cox [14]).

The Normal Containment (NC) coupons surprisingly recorded better results than the High Containment (HC) coupons. The lowest results were from the test coupon where the two bolt groups were brought closer together by reducing the spacing to $108 \mathrm{~mm}$. The amount of energy that the reduced spacing bolt group could absorb was also reduced.

The graph plots shown in Figure 5 shows the Maximum Connection System Force (MCSF) along with the amount of energy that each connection design was able to absorb. The error bars show the standard deviation of the mean.

The linear displacement is greater for the high containment coupon. This is because of the greater slot to margin dimension of $31.5 \mathrm{~mm}$ instead of the standard normal containment coupons that have a slot to margin dimension of $21.5 \mathrm{~mm}$. 
Table 4: Connection dynamic results.

\begin{tabular}{|c|c|c|c|c|c|c|c|c|}
\hline $\begin{array}{l}\text { Connection } \\
\text { Type }\end{array}$ & $\begin{array}{c}\text { Test } \\
\text { Coupon } \\
\text { Number }\end{array}$ & $\begin{array}{c}\text { Maximum } \\
\text { Connection } \\
\text { System } \\
\text { Force }(k N)\end{array}$ & $\begin{array}{c}\text { Absorbed } \\
\text { Energy } \\
\text { (J) }\end{array}$ & \multicolumn{5}{|c|}{$\begin{array}{l}\text { Failure Mode } \\
\left(\mathrm{T}=\mathrm{Tear} \quad \begin{array}{l}\mathrm{POS}=\mathrm{Plane} \text { Out } \\
\text { Shear) }\end{array}\right.\end{array}$} \\
\hline 4 Bolt NC & 1 & 239.28 & 1609 & POS & POS & POS & \multicolumn{2}{|c|}{ POS } \\
\hline 4 Bolt NC & 2 & 237.07 & 1572 & $\mathrm{~T}$ & POS & POS & \multicolumn{2}{|c|}{$\mathrm{T}$} \\
\hline 4 Bolt NC & 3 & 241.5 & 1694 & POS & POS & POS & \multicolumn{2}{|c|}{ POS } \\
\hline & Mean & 239.28 & 1625 & & & & & \\
\hline 4 Bolt $\mathrm{HC}$ & 1 & 223.57 & 1482 & $\mathrm{~T}$ & $\mathrm{~T}$ & $\mathrm{~T}$ & \multicolumn{2}{|c|}{$\mathrm{T}$} \\
\hline 4 Bolt HC & 2 & 211.48 & 1709 & $\mathrm{~T}$ & $\mathrm{~T}$ & $\mathrm{~T}$ & \multicolumn{2}{|c|}{$\mathrm{T}$} \\
\hline 4 Bolt $\mathrm{HC}$ & 3 & 201.42 & 1194 & $\mathrm{~T}$ & $\mathrm{~T}$ & $\mathrm{~T}$ & \multicolumn{2}{|c|}{ POS } \\
\hline & Mean & 212.16 & 1462 & & & & \multirow{2}{*}{\multicolumn{2}{|c|}{ POS }} \\
\hline 4 Bolt Reduced & 1 & 193.56 & 1180 & $\mathrm{~T}$ & $\mathrm{~T}$ & POS & & \\
\hline 4 Bolt Reduced & 2 & 143.81 & $\begin{array}{l}\text { incomp } \\
\text { lete }\end{array}$ & \multicolumn{5}{|c|}{ Void Test } \\
\hline 4 Bolt Reduced & 3 & 194.57 & 1240 & $\mathrm{~T}$ & POS & $\mathrm{T}$ & \multicolumn{2}{|c|}{ POS } \\
\hline & Mean & 194.07 & 1210 & & & & & \\
\hline 4 Bolt Holes & 1 & 231.02 & 1585 & POS & POS & POS & \multicolumn{2}{|c|}{ POS } \\
\hline 4 Bolt Holes & 2 & 237.67 & 1382 & POS & POS & POS & \multicolumn{2}{|c|}{ POS } \\
\hline 4 Bolt Holes & 3 & 247.74 & 1370 & POS & POS & POS & \multicolumn{2}{|c|}{ POS } \\
\hline & Mean & 238.81 & 1446 & & & & & \\
\hline 5 Bolt & 1 & 224.78 & 1596 & POS & POS & POS & POS & $\mathrm{T}$ \\
\hline 5 Bolt & 2 & 233.84 & 1523 & POS & POS & POS & POS & $\mathrm{T}$ \\
\hline 5 Bolt & 3 & 250.96 & 1923 & POS & POS & POS & $\mathrm{T}$ & $\mathrm{T}$ \\
\hline & Mean & 236.53 & 1681 & & & & & \\
\hline
\end{tabular}

\section{Discussion}

The failure modes for each connection are similar to those experienced within structural steel work members. Kulak et al. [6] conducted work into failure modes of structural connections with respect to load as a function of displacement. There were two distinct features of the load displacement curve, one being the transfer of the load by friction and the other by bearing of the bolts onto the member's cross section. In the graph plots shown in Figure 4 in particular, the phenomenon can be clearly seen. The transition between the two joint characteristics occurs in all of the test coupon types around the load of $50 \mathrm{kN}$ and at a linear displacement of $2.5 \mathrm{~mm}$. This is where the graph plots oscillate slightly. Steel shear connections are designed to transfer the load from one member to another (Astaneh-Asl [15]). Research by Ray et al [16] showed the same failure modes for a corrugated safety barrier beam tensile tested at quasi-static velocities 

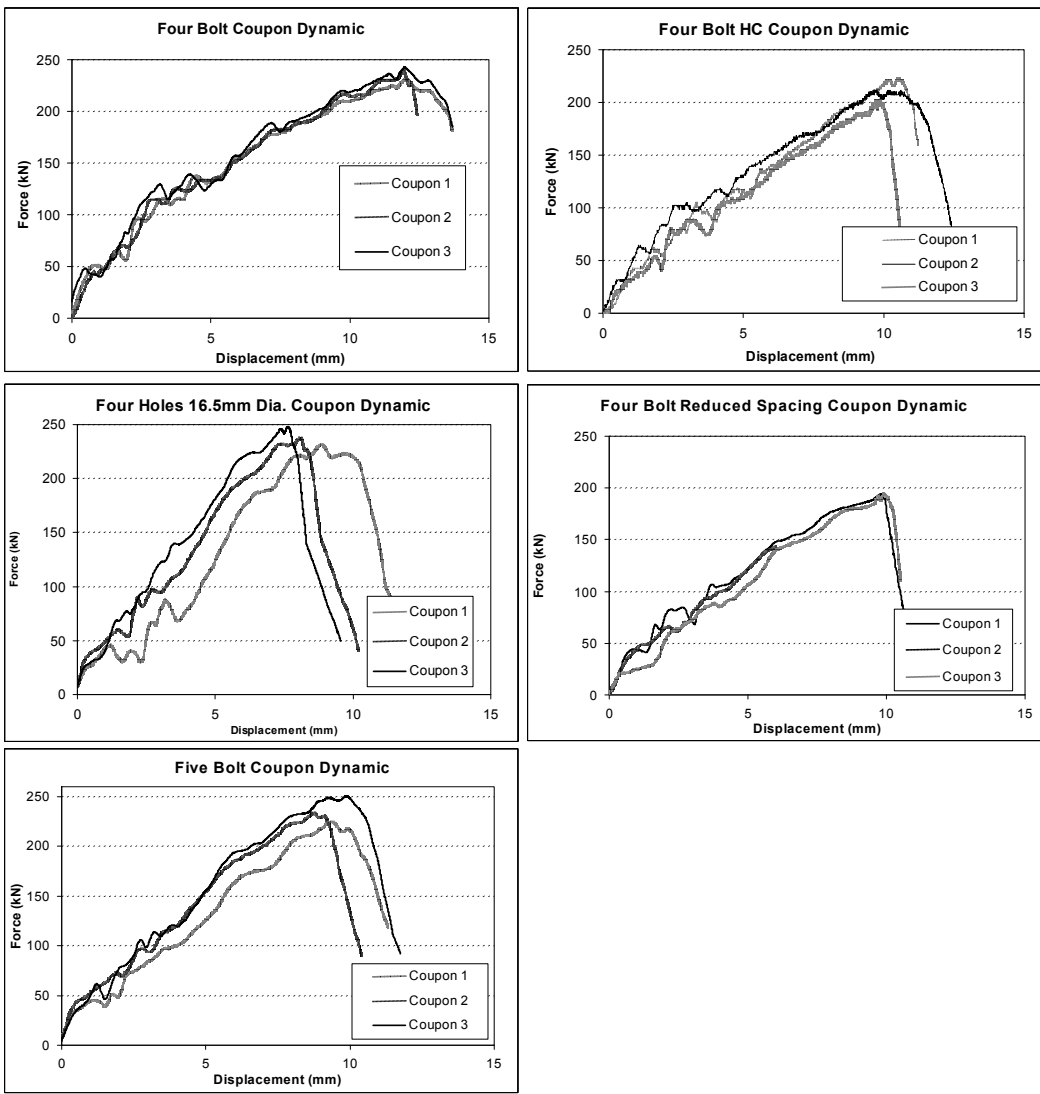

Figure 3: Dynamic force vs. displacement for connection test coupons.

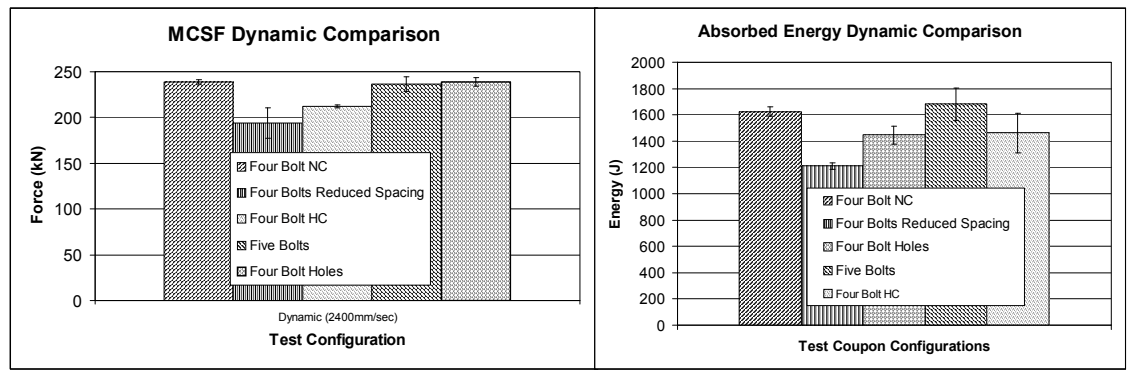

Figure 4: Connection performance comparisons.

Principally the five bolt connection returns the highest absorbed energy. However it is similar in MCSF to the standard four bolt and four bolt holes coupon. Looking at the force/displacement graph for the five bolt connection, it can be seen that the maximum load is reached within a reduced displacement 
when compared to the standard four bolt coupons. This means that there is less connection slip for a given displacement. Connection slip is defined as the movement in a connection when friction is overcome and the bearing of the component parts is initiated (Kulak et al. [6]). With this mind any slip between connecting members will affect the smooth transfer of load between members.

The test coupon that uses clearance holes $(\varnothing 16.5 \mathrm{~mm})$ instead of the standard safety barrier slots $(27 \mathrm{~mm} \times 29 \mathrm{~mm})$ gives the best connection performance for a four connection coupon. The increased cross sectional area would account for better performance but additionally the clamping force being exerted on the connection members would also be increased. Distortion of the connecting members upon tightening of the bolts was not evident in this particular coupon. The graph plot for this specific coupon, shown in Figure 4 demonstrates that the coupon reaches its maximum load with a very small displacement. This indicates that the bolt shanks come to bear on the section members almost instantaneously.

Finally the high containment coupon does not perform well in the dynamic tests. The graph plot in Figure 4 shows how the force/displacement curve is "flattened" considerably. The failure modes of the high containment test coupons consistently show that the tear failure mode was the predominant failure path. It may be the case that this failure mode leads the connection into a sequence of failure events that result in the connection being weaker overall.

The connection with a reduced spacing between the two bolt groups did not compare well to the other connections in terms of performance in the laboratory tests. Reducing the spacing between the bolt groups led to a reduction in absorbed energy as well as MCSF. Although the failure modes were consistent with the other test coupons, the point at which the two bolt groups come to bear on the connecting plates occurs sooner and the failure mode can be initiated earlier than with the other test coupon samples

\section{Conclusion}

In total, eighteen test coupons have been analysed to give an indication of the benefits that could be obtained from modifying the design of the road safety barrier lap joint connection. This paper gives an indication of the properties that may increase the performance of safety barrier systems. The following conclusions can be drawn from this study.

1. The five bolt connection absorbs more energy than any four bolt design.

2. Removing the slots and adding clearance holes increases connection strength.

3. Reducing the spacing between bolt groups is detrimental to connection performance.

4. Emphasis is also on the quality of the mechanical fastener components to stop the "tear" failure mode.

5. Failure mode can affect the linear displacement prior to failure in the connection. As a result this affects the amount of energy that can be absorbed. 


\section{References}

[1] British Standards Institute. 2000. BS EN 1317-1-2: Road restraint systems. London: BSI Publications.

[2] Birch, R.S. \& Alves M. 2000. Dynamic Failure of Structural Joint Systems. Thin Walled Structures. 36, (2) pp. 137-254.

[3] Tabei, A. \& Wu, J. 2000. Roadmap for crashworthiness finite element simulation of roadside structures. Finite elements in analysis and design. 34 (2), pp. 145-157.

[4] Su, R.K.L \& Siu, W.H. 2006. Non-linear response of bolt groups under inplane loading. Engineering Structures 29, (4) pp. 626-634.

[5] Reid, J.D. \& Hiser N.R. 2005. Detailed modelling of bolted joints with slippage. Finite elements in analysis and design. 9 (1), pp. 547-562.

[6] Kulak, G.F. Fisher, J.W. \& Struik J.H.A. 1987. Guide to design criteria for bolted and riveted Joints. 2nd edn. New York: John Wiley \& Sons.

[7] Bayton, D.A.F. Fourlaris, G. \& Jones, T.B. 2008. Safety Barrier Connection Joint Post Test Analysis. Materials and Design. Elsevier Publishing. 29 (5), pp. 915-921.

[8] Oberg, E. Jones F.D. Horton H.L. \& Ryfel H.H. 1996. Machinery's Handbook. 25th edn. New York: Industrial Press Inc.

[9] British Standards Institute. 2004. BS EN 10025-1:2004. Hot rolled products of structural steel. London: BSI Publications.

[10] Dieter, G. E. 1988. Mechanical Metallurgy. 4th edn. McGraw-Hill: London.

[11] Bickford, J.H. 1974. An Introduction to the design and behaviour of bolted joints. New York: Marcell Dekker Inc.

[12] Shigley, J.E. \& Mischke, C.R. 1989. Mechanical Engineering Design. 5th edn. London: McGraw-Hill.

[13] Nethercott, D.A. 1996. Limit states design of structural steelwork. 2nd edn. London: Chapman \& Hall.

[14] Cox, M.G. 2007. The area under a curve specified by measured values. Metrologia 44. pp. 365-378

[15] Astaneh-Asl, A. \& Liu, J \& McMullin, K.M. 2002. Behaviour and design of single plate shear connections. Journal of Constructional Steel Research. 58 (5-8), pp. $1121-1141$.

[16] Ray, M.H. Engstrand, K. \& Plaxico, C.A. 2001. Performance of w-beam splices. Massachussetts: Worcester Polytechnic Institute. 